\title{
Age and Gender Effects on Resilience in Children and Adolescents
}

\author{
Jing Sun and Donald Stewart
}

\author{
Author details \\ Dr Jing Sun (corresponding author) \\ School of Public Health, Logan Campus, Griffith University, University Drive, \\ Meadowbrook, Queensland 4131, Australia \\ j.sun@griffith.edu.au, or jingsun@optusnet.com.au
}

Professor Donald Stewart

School of Public Health, Griffith University.

\section{Acknowledgement:}

The authors gratefully acknowledge funding support for this project from Queensland Health. 


\title{
Age and Gender Effects on Resilience in Children and Adolescents
}

\author{
Authors: Jing Sun and Donald Stewart
}

\begin{abstract}
This cross-sectional, population based study explores the effect of age and gender on resilience and protective factors for mental health in primary school aged children in Brisbane, Australia. Surveys were administered to 1109 male and 1163 female students $(\mathrm{N}=2492)$ in 2004 to assess self-perception of resilience and associated protective factors. Female students are found to be more likely to report higher levels of communication, empathy, help-seeking, and goals for future and aspirations. They also report more positive connections with parents, teachers and adults in the community, and peers in school and outside school, as well as sense of autonomy experience. These differences, however, show changes over time. The interaction between age and gender is significant for empathy and help-seeking, and for adult support at home, at school and in the community, peer support at school and outside schools, and autonomy experience. This is largely explained by the sharp decline in scores for Year 7 girls. The gender differences in individual characteristics and protective factors for primary school children deserve further investigation, in view of their potential implications for mental health prevention and promotion.
\end{abstract}

Keywords: age, gender, resilience, individual characteristics, protective factors, resilience 


\title{
Age and Gender Effects on Resilience in Children and Adolescents
}

\author{
Jing Sun and Donald Stewart
}

\section{Introduction}

Prior research has shown that children and adolescents are exposed to a variety of risk factors (Luthar \& Cicchetti, 2000). Risk factors have been defined as hazards relating to the individual or the environment that increase the likelihood of a problem occurring (Rutter, 1987b). Findings indicate that school-related risk factor are most frequently reported, followed by individual risk factors such as low self-esteem and empathy (Wild, Flisher, Bhana, \& Lombard, 2004), and also environmental risk factors such as conflicts with peers, low support from parents and teachers (Ackerman, Brown, \& Izard, 2004; Doll \& Lyon, 1998; McBride, 1995). Further, studies have found that these risk factors are significantly related to mental health problems (Doll \& Lyon, 1998). Thus, daily risk factors, especially when experienced in a cumulative manner, appear to be linked to mental health problems (Doll \& Lyon, 1998). Numerous studies emphasize that enhanced risk factors of present day children and adolescents are related to the remarkable rise in rates of adolescent suicide, depression, and substance abuse (Beam, Gil-Rivas, Greenberger, \& Chen, 2002; Plancherel \& Bolognini, 1995; Storksen, Roysamb, Moum, \& Tambs, 2005).

Research in psychopathology has provided evidence for the significant role of resilience, particularly when it has conceptualised as successful adaptation despite risk. For example, resilience has been used to characterise individuals who overcome difficult and challenging life circumstances and risk factors (Garmezy, Masten, \& 
Tellegen, 1984; Rutter, 1984; Werner, 1992). This perspective leads to the conclusion that low levels of individual characteristics such as low self-esteem and self-concept; and environmental factors such as low level of social support is a significant risk factor for the psychological development in children and adolescents (Beam et al., 2002; Plancherel \& Bolognini, 1995; Storksen et al., 2005).

\section{Operationalisation of resilience}

The literature on resilience among children and adolescents resilience tends to be dichotomized (Benard, 1997, 2004) into individual focused characteristics and protective factors. In general, individually focused characteristics are identified via strategies directed towards modifying internal goals, problem solving strategies, and feelings of self-worth. Protective factors, on the other hand, focus on coping, and are reflected via strategies directed towards regulating or modifying external resources or support.

\section{Efficiency of resilience strategies}

Studies of children and adolescents have found that both individual characteristics and environmental factors may be negatively related to mental health problems (Torsheim, Aaroe, \& Wold, 2001; Tusaie, Puskar, \& Sereika, 2007). These associations indicate that self-esteem, peer support, parent support, and social participation are important to children's mental health status. Moreover, in longitudinal studies, the development of adolescent depression has been found to be predicted by low levels in self-esteem and social support (Torsheim et al., 2001; Tusaie et al., 2007). Further research (Broderick \& Korteland, 2002; Smith \& Carlson, 1997) suggests that the efficiency of resilience strategies is significantly influenced by the individual's perceived autonomy in coping 
with risk factors. Thus, more positive adjustment was shown when efficacy and autonomy was employed to deal with risk factors which were perceived to be controllable. In addition, seeking support in relation to uncontrollable risks was associated with fewer mental health problems.

\section{Age and Gender Effects on resilience}

In order to understand the significance of resilience factors in coping with risk factors, several studies have focused their attention on the influence that individual characteristics such as age and gender have on individual's ability to cope with risk factors within their environment.

\section{Age Effects}

Most studies of developmental change have found that increases in individual resilience factors such as self-esteem are age-dependent among children and adolescents (aged 5 to 17 years) (Bolognini, Plancherel, Bettwshart, \& Halfon, 1996; Frost \& McKelvie, 2004; Watkins, Dong, \& Xia, 1997). Further studies confirm this finding, showing that self-esteem is lower in younger children. However, a few studies of 9-14 year old children and adolescents have found decreases in self-esteem with increasing age, suggesting that the relevant individual characteristics are acquired in middle childhood. In contrast, results in terms of developmental changes related to environmental factors are less consistent.

Extensive research has been conducted in recent years to investigate the important relationships between children's resilience, their environments and their mental health and well-being (Garmezy et al., 1984; Luthar, 2003; Werner, 1990). Resilience has been used to characterise individuals who overcome difficult and challenging life circumstances and risk factors (Garmezy et al., 1984; Luthar, 2003; Rutter, 1984; 
Werner, 1992). This perspective has conceptualised resilience as successful adaptation, despite risk. Risk factors have been defined as hazards relating to the individual or the environment that increase the likelihood of a problem occurring (Rutter, 1987a).

\section{Gender effects}

Prior studies indicate that gender has a notable effect on a child's coping strategies (2, 3). Coping strategies can be categorised into two basic types; maladaptive and adaptive strategies (P. Hampel \& Petermann, 2005). Younger boys and girls, and boys from all age groups tend to make more use of adaptive coping strategies that focus on the immediate problem. Strategies are externalised and commonly include direct action, distraction and positive self-instruction (P. Hampel \& Petermann, 2005; P. Hampel \& Petermann, 2006).

There is also evidence that girls cope with daily stressors by seeking social support and utilising social resources (Frydenberg \& Lewis, 1993). In contrast, boys use physical recreation such as sport to cope with adversity (Frydenberg \& Lewis, 1993). Despite being under stress, girls have been found to use resilience factors such as seeking and getting support more than boys, with Grotberg finding that girls used these resilience factors more than boys (P. Hampel \& Petermann, 2005).

The studies mentioned above focused on older children, but few studies have examined age and gender differences in resilience in primary school aged children in Australia. In the current study, the effects of gender and age (late childhood, early, and middle adolescence) on resilience, within 2 domains (individual characteristics and protective factors) were investigated. It was hypothesized that (1) girls would employ more individual focused strategies and protective factor focused strategies 
than boys. (2) Middle childhood would have higher scores than early adolescence in both individual characteristics and protective factors;

\section{Methods}

\section{Research design}

A cross-sectional design was employed to analyse a cohort of children in 20 government and Catholic school communities as part of a three-year, multi-strategy health promotion project. The project was oriented around a whole-school approach to promoting resiliency in children of primary school age in school, family and community settings.

\section{Subjects}

The study sample comprised 1109 male and 1163 female students attending Years $3(n=816), 5(n=816)$ and $7(n=860)$ from 15 public schools and 3 Catholic Schools in northern and southern Brisbane, Australia in 2004, representing a response of $90 \%$ of the invited sample. Their ages ranged from 8-12 years $($ mean $=10.04)$. The mean age of this student sample was 8.42 years $(S D=1.24)$ for Year 3 students, 10.04 years $(\mathrm{SD}=0.39)$ for Year 5 students, and 12.05 years $(\mathrm{SD}=.41)$ for Year 7 students.

Comparison of the sample in relation to gender and age with the 2002 census sample showed that sample was representative of the population from which it was drawn in regard to gender and age.

\section{Instruments}

All the measures referred to are self-reported and identical at each age.

Resiliency scale:

Resilience was assessed by a Resilience Scale modified from the California Healthy Kids Survey (California Department of Education, 2004). The Resilience Scale assessed student responses on five subscales of individual characteristics and 
seven subscales of protective factors. The individual characteristics consist of: (1) communication and cooperation; (2) self-esteem; (3) empathy; (4) help seeking behaviour, (5) goals and aspirations (for details of the items see appendix 1). The Resilience Scale comprised a total of 13 questions on a 5-point scale with scores ranging from 1 to 5, with higher scores indicating more resilience. Cronbach’s alpha shows a high level of internal reliability for subscales 1 and 2 of the Resiliency Scale (.84 and .72) and for the total scale (.84).

\section{Protective Factor Scale:}

Protective factors were measured using the Protective Factor Scale from the California Healthy Kids Survey (California Department of Education, 2004) and a modified version of the Perception of Peer Support Scale (Ladd, 1999). The protective factors consist of: (1) family support, (2) school support, (3) community support, (4) autonomy experience, (5) prosocial relationship with peers, (6) meaningful participation in extra-curricula activities, and (7) peer support. The protective factors assess children's perceptions about support from adults and peers at home, school and in the community, their autonomy experience, and the extent of their meaningful participation in social activity. Examples of the items in relation to the subscales of protective factors included: “adults at home are interested in my (the student's) school work"; “(they) believe that I will be a success”. Examples of the items in relation to Peer Support included: “Are there students at your school who would: choose you on their team at school”, “...tell you you're good at doing things”. (for details of the items see appendix 1). Confirmatory factor analysis showed that the data from the Protective Factor Scale fits the model and that the scale had RMSEA (root mean square error of approximation) values of less than .05 and a CFI (comparative fit index) value of more than .94. For the Perception of Peer Support Scale, exploratory 
factor analysis extracted one construct, “peer support”. Cronbach’s alpha showed a high level of internal reliability for the total scale (.91).

\section{Procedure}

The student survey consisted of a self-reported questionnaire on: empathy, communication and cooperation; self-efficacy and problem solving; adult support at home; adult support in school; adult support in the community; peer support; friends outside schools; and meaningful participation in social activities. Data from the student sample were collected by the classroom teachers.

The investigators provided school administrators with a sample parental notification letter, informing parents about the project and giving them and their child the opportunity of signing the form if they did not wish their child to participate in the study. Students for whom the notification was received were excluded from the survey. Following this, a consent form was given to each student before the actual survey started. Approximately $10 \%$ of the eligible students either were absent from school or did not complete more than $50 \%$ of the questions. These students were not included in the study. Therefore, the final sample consisted of approximately $90 \%$ of the Year 3, 5 and 7 students in 18 primary schools.

The questionnaire was administered by trained class teachers during the school day and in the classroom setting in order to maximize participation. The investigators explained the procedures and answered any questions about the assessment measures in staff meetings to the class teachers. Students were given 30-40 minutes to complete the questionnaires. The completion of the questionnaire was voluntary and anonymous and students were informed that: (1) responses would not be seen by parents or school staff, (2) responses would be private and students should not attempt to see others' answers or discuss responses while the survey way being administered, 
(3) students had the right not to answer the questions if they felt uncomfortable about them (4) students should try to answer the questions honestly.

Further details of these procedures and their reliability are found in Sun and Stewart (2007).

\section{Analysis}

All data were analysed using the SPSS package version 14.0. Individual characteristics and protective factor variables included in the analyses are continuous, and age and gender are categorical. The differences between boys and girls, differences between students in Years 3, 5 and 7, and the interactions between age and gender were analysed by multivariate analysis of variance (MANOVA). Effects on the 13 subscales were detected by univariate analyses of variance (ANOVAs). With regard to multiple tests, only results of univariate analyses with $p<.01$ are considered.

\section{Results}

Table 1 shows the differences between boys and girls for resiliency and protective factors.

\section{INSERT Table 1}

\section{Gender effect}

Gender has a significant effect on individual factors (Wilk’s Lambda $F=41.96, p$ $<.001$ ). The results of univariate variance of analysis (Table 1) further shows that the subscale of communication, empathy, help-seeking, and goals and aspirations contributes significantly to the differences between boys and girls on the individual 
factors, where boys had lower scores than girls in terms of communication, empathy, help-seeking, and goals and aspirations.

Gender also has a significant effect on protective factors as measured by the Protective Factor Scale (Wilk's Lambda $F=24.42, p<.001$ ). Univariate analysis of variance further shows (Table 2) that all subscales except "prosocial peers” and "meaningful participation in social activities" significantly contribute to the differences between boys and girls in terms of protective factors, where boys show lower scores than girls.

\section{Age effect}

Tables 1 and 2 shows the differences between Year 3, 5 and 7 students for the individual characteristics and protective factors subscales. Age has significant effects on overall individual characteristics $(F=23.46, p<.001)$, and protective factors $(F=$ $16.85, p<.001)$.

Univariate analysis of variance further shows that four subscales of individual factors contributed to the significant differences between Year 3, 5, and 7 students. Year 3 students (8 year olds) showed significantly higher scores than both Year 5 (10 year olds) and Year 7 students (12 year olds) on the communication, empathy, helpseeking; whereas Year 5 students had higher scores than Year 3 and 7 students on goals and aspirations subscale.

Univariate analysis of variance shows that all of the subscales of the protective Factor Scale contributed to the significant differences between Year 3, 5 and 7 students. Table 1 shows the inconsistent patterns in the differences between these three age groups, in which Year 5 students had higher scores in family support, community support than Year 3, the scores in peer support significantly increased 
with age. The scores in school support, prosocial peers, autonomy experiences, and meaningful participation in activities significantly decreased with age.

All results were confirmed by analyses of variance. 


\section{Age and Gender Interaction}

Because MANOVAs revealed main effects of age group and gender, an additional MANOVA was performed to determine the interaction effect of age group by gender. Thereby, a significant interaction effect was found (Wilks's $F(10,5058)=2.55, \mathrm{P}<$ $.01)$ for individual factors, and (Wilks's $F(12,5056)=2.83, \mathrm{P}<0.001)$ protective factors.

The Resilience subscales on empathy and help-seeking contributed significantly to the age and gender interaction, as shown in Table 1 . The scores for empathy and help-seeking decrease with age in general, with girls having higher scores than boys. However, boys show greater decreasing scores with age than girls.

All of the protective factor subscales except 'family support' and 'community support' contributed to the significant interaction between age and gender in students. Post hoc students' t tests revealed that interaction effects were mostly explained by females in Year 7. Thus, with regards to individual characteristics, girls in early adolescence (Year 7) used less communication, showed less esteem and empathy, sought less help from other people, showed less goals and aspirations than girls in early (Year 3) and middle childhood (Year 5). With regards to protective factors, girls in early adolescence felt they had less school support, had less prosocial peers, participate less and had less autonomy than Year 3 and Year 5 girls. In contrast, girls in early adolescence in Year 7 had more peer support thanYears 3 and 5.

Compared to their male counterparts, girls in the early adolescence scored higher on communication ( $\mathrm{t}=4.44, \mathrm{P}<0.001)$, empathy $(\mathrm{t}=7.33, \mathrm{P}<0.001)$, and helpseeking $(\mathrm{t}=4.82, \mathrm{P}<0.001)$ of individual characteristics, and family support $(\mathrm{t}=$ 2.59, $\mathrm{P}<0.01)$, school support $(\mathrm{t}=4.98, \mathrm{P}<0.001)$, community support $(\mathrm{t}=2.98, \mathrm{P}<$ 0.05), autonomy experience $(\mathrm{t}=5.13, \mathrm{P}<0.001)$, and peer support $(\mathrm{t}=7.18, \mathrm{P}<$ 
0.001). In respect to male individual characteristics, early adolescent boys scored lower than year 3 students on communication $(\mathrm{F}=11.26, \mathrm{P}<0.001)$, empathy $(\mathrm{F}=$ 20.15, $\mathrm{P}<0.001)$, and help-seeking $(\mathrm{F}=29.99, \mathrm{P}<0.001)$. With regards to protective factors, early adolescent boys score lower than year 3 students on school support ( $\mathrm{F}=$ 25.69, $\mathrm{P}<0.001)$, autonomy experience $(\mathrm{F}=17.87, \mathrm{P}<0.001)$, prosocial peers $(\mathrm{F}=$ 15.25, $\mathrm{P}<0.001)$, and meaningful participation $(\mathrm{F}=15.25, \mathrm{p}<0.001)$.

\section{Discussion}

This research demonstrates the impact of age and gender on scores of resilience for primary school students. The interaction between age and gender is significant for empathy and help-seeking of individual characteristics, and significant school support, peer support, prosocial peers, meaningful participation in school activities, and autonomy experience.

\section{Gender differences}

In this study, female students have consistently been found to have higher scores than boys for individual characteristics in communication, empathy, help-seeking and goals and aspirations. They are also more likely to report positive connections with parents, teachers, and adults in the community, peer relations and autonomy experiences, than boys. There is no difference in self-esteem between girls and boys. The results of this study regarding gender differences in self-esteem is inconsistent with those of other studies which indicate for younger children that in terms of selfesteem, girls have higher scores than boys (Bolognini et al., 1996; Watkins et al., 1997). The higher scores in girls than boys in communication, empathy, help-seeking and goals and aspiration which are related to social relations and social skills development are consistent with previous studies (Broderick \& Korteland, 2002; 
Frydenberg \& Lewis, 1993; P. Hampel \& Petermann, 2005). The gender differences in resilience found in the study indicate the emergence of gender-specific behavioural characteristics at primary school age, such as girls having a more positive level of social emotional development (communication, empathy, help-seeking and autonomy experience) and a higher level of caring relations with adults and peers and social support than boys.

Relational theory views girls as tending to explore who they are in relation to others rather than in isolation (Miller, 1986) and seeking out mutually empathic connections in all primary relationships. Miller (1986) claims that a fundamental aspect of a girl's psychological growth is seeing herself as a relational entity. This perspective assumes that positive outcomes will result from these relationships, such as better communication, positive feelings about self and strong identity (Belgrave, Chase-Vaughn, Gray, Addison, \& Cherry, 2000). Findings in this study support this notion. More contemporary theories have portrayed males as competitive, taskoriented in problem solving, especially in work domains, and females as prosocial, and empathic copers especially in interpersonal domain. Based on the findings of the current study, it may be the case that female students use more emotionally focused strategies than boys such as communication strategies, empathy, and help-seeking, they also showed wishful thinking such as having goals and aspirations.

\section{Age differences}

An additional issue to consider is how the actual level of children's perceptions on individual characteristics and protective factors changes with age. The results from the current study indicate that younger and older primary school students showed different patterns relating to different aspects of individual characteristics and 
protective factors. For example, early childhood (Year 3) students scored significantly higher than both Year 5 and 7 students for communication, empathy, and help-seeking, school support, prosocial peers, meaningful participation in school activities, and autonomy experiences. It seems that expectancies and beliefs decrease during the elementary years in terms of these resilience factors. This may be because younger students' coping strategies are acquired in the early years of primary school, such as belief in the usefulness and importance of communication and cooperation, empathy, help-seeking skills, seeking adult support in school for academic and nonacademic activities, having prosocial friends or peers, actively participating in school activities, and gaining more experience in autonomy. The decreasing scores in these areas may be due to reduced use of these strategies to deal with stressful events. This may be replaced by wishful thinking (goals and aspiration), seeking family and community support, and peer support. This is indicated by higher scores in Year 5 than Year 3 and 7 students in goals and aspiration, family support, community support and peer support. It appears that expectancies and beliefs increase during the elementary years in terms of wishful thinking, and their beliefs about the importance and usefulness of having support from adults at home, having support from adults in communities, having peer support at school, and having opportunities to participate a variety of activities increase over time as the children get older. The possible explanation for this is that the older students' competence beliefs for success, such as problem solving, increase over time (DuBois et al., 2002; Jacobs, Lanza, Osgood, Eccles, \& Wigfield, 2002), and that increasingly peer-oriented and familial oriented patterns of support are predictive of emotional development (DuBois et al., 2002; Jacobs et al., 2002). 
Year 7 students had lower scores in all of the individual characteristics and protective factors. In a discussion of the development of resilience during early adolescence, it should be noted that adolescence involves transition and is a period when young people must re-define themselves in many areas. Firstly the experience of bodily changes (puberty), in mental abilities, and in social relationships (family, school, and friends). Secondly, early adolescence is a period where the young person begins to pay more attention to him/herself, and introspection now plays an important role. It is, therefore, reasonable to expect changes in the evaluation of self at this time, and evaluation of other areas of social experiences, such as family, schools, society, and peers. For these reasons, early adolescence is a time when resilience may be especially liable to fluctuation.

\section{Age and gender interaction}

Changes occurring over time in individual and protective factors for girls were significantly different from those of boys. Age and gender showed significant interaction in such resilience factors as empathy and help-seeking, and in protective factors such as adult support, school support, prosocial peers, peer support, meaningful participation, and autonomy experience. With increasing age, girls consistently had higher scores than boys for all these factors. Specifically, the scores for the resilience subscales in school support, communication, empathy, help-seeking, goals and aspirations decreased with age for boys, whereas they increased from Year 5 to Year 7 in family support, community support, peer support, and self-esteem. The scores in all subscales except peer support increased with age for girls from Year 3 to Year 5 but decreased from Year 5 to Year 7. The girls in Year 5 had higher scores in the communication, empathy, help-seeking, family support, community support, esteem, and goals and aspiration than girls in Year 3 and 7. It is possible that these 
trends may indicate that Year 5 is the critical time for girls to gain such skills influencing their perception of self to communicate and cooperate with others, and influencing their perception of social support from family and community, selfesteem and goals and aspirations (Belgrave et al., 2000).

The increasing self-esteem score in boys and decreasing score in girls is consistent with previous studies (Bolognini et al., 1996; Watkins et al., 1997) that indicate that in early adolescence girls show lower self-esteem than boys.

An answer to the question: Why are girls different from boys in terms of communication, empathy, help-seeking, goals and aspirations, and why does this difference change with age? This may be found in the differing patterns of socioemotional development in girls and boys in childhood. The individual characteristics of development such as communication, empathy, help-seeking skills and goals and aspiration are required in the processes accounting for social support (DuBois et al., 2002). For students experiencing the transition from childhood to adolescence, adequacy in communication with adults in families and at schools and in the community and the possibility of being able to express opinions and feelings freely, becomes an important element of stress mediation (Smith \& Carlson, 1997). Moreover, the social support one receives during childhood can positively affect development (Jacobs et al., 2002; Roeser, Eccles, \& Sameroff, 2000). Although these proposed linkages need to be tested longitudinally, the results of this study provide evidence for the ways individual characteristics and protective factors can work together to promote mental health in children.

For boys, their belief in the importance and usefulness of empathy, communication and cooperation decreases with age. This suggests that boys become less interested in using social strategies such as empathy, communication and 
cooperation to solve problems. For girls, however, they favour strategies associated with empathy, communication and cooperation to express themselves, to seek help and for solving problems. As indicated in previous studies, boys take a different path in developing their self-concept from girls, as boys develop their identities through a process of separation and autonomy whereas a girl's development is one of becoming a person of relationships, a 'self with others' (Gilligan, 1982). Heyman and Legare (2004) also report that girls are more prosocial than boys, and boys are more individual and autonomous than girls, suggesting the developmental trends in resilience factors in girls and boys show different patterns, with boys being more problem solving and individually oriented, whereas girls are more social and interrelational oriented.

The increasingly significant difference between boys and girls with age in individual characteristics and protective factors in resilience, may be explained by the period of gender-role intensification in early adolescence, when boys and girls will be pressured to adopt more difference in their interests, domain values and activities (Bolognini et al., 1996; Hill \& Lynch, 1983); it may also be because early adolescence coincides with a time of important choices concerning school courses, extra-curricular or leisure-time activities, life-style, and choices in social relationships and friendships. For these reasons, early adolescence is a time when resilience is especially necessary as a healthy foundation, but needs to be gender sensitive in order to enable the person to make adequate choices.

The decreased scores for girls from Year 5 to Year 7 is different from boys who showed more steady development from Year 5 to Year 7 in individual characteristics and protective factors of resilience. 
In summary, this study has found that female students are more likely to report higher levels of empathy, communication and cooperation, and positive connections with parents, teachers, adults in the community, with peers in school and outside school, and autonomy experiences. Also, it has found that these differences show changes over time. The age and gender interaction is significant for empathy, communication and cooperation and for support from adults at home, school and community, peer support at school and outside school and autonomy experience.

\section{Implication, Limitations and Final Conclusions}

There is limited research into the age and gender effect on resilience in primary school aged children and this paper provides an initial opportunity to study this important area. However, some limitations are apparent. First, on the basis of the sample examined in this study, findings are restricted on resilience in the Australian culture. Despite a number of cross-cultural studies that revealed similar results on resilience in North American and European samples (Frydenberg \& Lewis, 1993; Prelow, Weaver, \& Swenson, 2006), cultural differences cannot be ruled out. Second, resilience has been assessed by a self-report questionnaire, but other informants were not included. Third, more contemporary theories have portrayed males as competitive and task-oriented in problem solving, especially in work domains, although these questions were not adequately assessed in this study. Important factors such as problem focused coping strategies, sports, academic interests in children, have to be acknowledged in future studies to improve the understanding of age and gender effects on resilience. Conclusively, however, the results of this study support the multidimensional operationalization of resilience. Thereby, inconsistent findings of studies examining effects of age and gender on resilience styles can be partly 
explained by methodological differences. Furthermore, by applying this multidimensional approach to evaluation, resilience patterns, whose clinical relevance has been shown, can be detected. Thus, more specific assessments of individual resources and deficits in resilience, better adjustments of intervention programs to diagnosed coping patterns, and more comprehensive evaluations of intervention programs are available. Finally, findings warrant further investigations of the interaction effects of age and gender on resilience. With such information, early adolescents who were identified as a risk population could be specifically supported by preventive mental health care in Australia, or elsewhere. 
Table 1. Individual characteristics of Resilience factors by age and gender interaction in Year 3, 5 and 7 male and female students

\begin{tabular}{|c|c|c|c|c|c|c|c|c|c|}
\hline & \multicolumn{3}{|c|}{ Males } & \multicolumn{3}{|c|}{ Females } & \multicolumn{3}{|c|}{$\begin{array}{c}\text { Factor } \\
\text { F }\end{array}$} \\
\hline & Year 3 & Year 5 & Year 7 & Year 3 & Year 5 & Year 7 & Age & gender & Age by \\
\hline & $\mathrm{M}(\mathrm{SD})$ & M(SD) & $\mathrm{M}(\mathrm{SD})$ & $\mathrm{M}(\mathrm{SD})$ & $\mathrm{M}(\mathrm{SD})$ & $\mathrm{M}(\mathrm{SD})$ & & & gender \\
\hline & $(\mathrm{N}=450)$ & $(\mathrm{N}=449)$ & $(\mathrm{N}=442)$ & $(\mathrm{N}=433)$ & $(\mathrm{N}=465)$ & $(\mathrm{N}=497)$ & & & \\
\hline Communication & $4.20(0.74)$ & $4.01(0.72)$ & $3.98(0.68)$ & $4.34(0.66)$ & $4.29(0.61)$ & $4.16(0.60)$ & $19.19 * * *$ & $55.84 * * *$ & 2.39 \\
\hline Self-esteem & $4.08(0.81)$ & $4.05(0.74)$ & $4.08(0.74)$ & $4.19(0.73)$ & $4.22(0.61)$ & $4.10(0.65)$ & 1.14 & $11.61 * * *$ & 2.67 \\
\hline Empathy & $3.99(1.01)$ & $3.65(1.04)$ & 3.57 (0.99) & $4.31(0.86)$ & $4.26(0.76)$ & $4.10(0.77)$ & 26.31*** & $187.02 * * *$ & $5.58 * *$ \\
\hline Helpseeking & $3.92(0.97)$ & $3.53(1.00)$ & $3.40(1.07)$ & $4.10(0.88)$ & $3.98(0.83)$ & $3.72(0.94)$ & $48.41 * * *$ & $69.48 * * *$ & $4.51 *$ \\
\hline Goals and aspirations & $4.21(0.93)$ & $4.28(0.90)$ & $4.24(0.88)$ & $4.31(0.88)$ & $4.44(0.69)$ & $4.27(0.78)$ & $4.13^{*}$ & $7.67 * *$ & 1.13 \\
\hline
\end{tabular}


Table 2. Protective factors of Resilience by age and gender in Year 3, 5 and 7 students

\begin{tabular}{|c|c|c|c|c|c|c|c|c|c|}
\hline & & Males & & & Females & & & $\begin{array}{c}\text { Factor } \\
\text { F }\end{array}$ & \\
\hline & $\begin{array}{c}\text { Year } 3 \\
\text { M(SD) } \\
(\mathrm{N}=450)\end{array}$ & $\begin{array}{c}\text { Year } 5 \\
\mathrm{M}(\mathrm{SD}) \\
(\mathrm{N}=449)\end{array}$ & $\begin{array}{l}\text { Year } 7 \\
\mathrm{M}(\mathrm{SD}) \\
(\mathrm{N}=442)\end{array}$ & $\begin{array}{l}\text { Year } 3 \\
M(S D) \\
(N=433)\end{array}$ & $\begin{array}{c}\text { Year } 5 \\
\text { M(SD) } \\
(\mathrm{N}=465)\end{array}$ & $\begin{array}{c}\text { Year } 7 \\
\mathrm{M}(\mathrm{SD}) \\
(\mathrm{N}=497)\end{array}$ & Age & gender & $\begin{array}{l}\text { Age by } \\
\text { gender }\end{array}$ \\
\hline Family support & $4.28(0.73)$ & $4.34(0.65)$ & $4.34(0.68)$ & $4.38(0.67)$ & $4.54(0.52)$ & $4.44(0.67)$ & $6.43^{* *}$ & $26.36 * * *$ & 1.68 \\
\hline $\begin{array}{l}\text { Adults support at } \\
\text { school }\end{array}$ & $4.16(0.83)$ & $3.82(0.99)$ & $3.73(0.87)$ & $4.26(0.77)$ & $4.23(0.71)$ & $3.98(0.83)$ & $36.57 * * *$ & $61.63^{* * *}$ & $7.38^{* *}$ \\
\hline $\begin{array}{l}\text { Adult support in } \\
\text { community }\end{array}$ & $4.38(0.71)$ & $4.44(0.77)$ & $4.44(0.74)$ & $4.46(0.71)$ & $4.65(0.50)$ & $4.55(0.67)$ & $6.25^{* *}$ & $23.97 * * *$ & 2.12 \\
\hline Peer support & $3.82(0.90)$ & $3.70(0.89)$ & $3.71(0.88)$ & $4.00(0.80)$ & $4.08(0.79)$ & $4.16(0.75)$ & 0.56 & $102.19 * * *$ & $5.84^{* *}$ \\
\hline Prosocial peers & $3.68(0.66)$ & $3.49(0.65)$ & $3.46(0.55)$ & $3.64(0.62)$ & $3.63(0.49)$ & $3.49(0.54)$ & $20.82 * * *$ & 3.02 & $5.52 * *$ \\
\hline $\begin{array}{l}\text { Meaningful } \\
\text { participation }\end{array}$ & $3.68(0.66)$ & $3.49(0.65)$ & $3.46(0.55)$ & $3.64(0.63)$ & $3.64(0.49)$ & $3.49(0.54)$ & $20.82 * * *$ & 3.02 & $5.52 * *$ \\
\hline $\begin{array}{l}\text { Autonomy } \\
\text { experiences }\end{array}$ & 3.60 (0.98) & $3.29(0.86)$ & $3.26(0.87)$ & $3.80(0.88)$ & $3.74(0.77)$ & $3.60(0.73)$ & $21.89 * * *$ & $95.52 * * *$ & $4.65 * *$ \\
\hline
\end{tabular}

Note: Abbreviations of subscales see appendix 1.

$* p<.05 ; * \star p<.01 ; * * \star p<.001$. 
Appendix 1

\section{Individual characteristics}

\section{Factor 1: Communication}

22. I help other people

23. I enjoy working with other students

24. I stand up for myself

Factor 2: Self-esteem

25. I can work out my problems

26. I can do most things if I try

27. There are many things that I do well

Factor 3: Empathy

28. I feel bad when someone gets their feelings hurt

29. I try to understand what other people feel

\section{Factor 4: Helpseeking}

30. When I need help, I find someone to talk to

31. I know where to go for help when I have a problem

32. I try to work out problems by talking about them

Factor 5: Goals and Aspiration

33. I have goals and plans for future

34. I think I will be successful when I grow up

\section{Protective Factor}

\section{Factor 1: Peer Support}

14. Are there students ask you to play when you are alone?

15. Are there students tell you you're their friend?

16. Are there students make you feel better if something is bothering you?

17. Are there students help you if other students are being mean to you?

18. Are there students pick you for a partner?

19. Are there students help you if you hurt yourself in the playground?

20. Are there students share things like stickers, toys and games with you?

21. are there students invite you to play at their home?

22. Are there students miss you if you weren't at school?

23. Are there students tell you secrets?

24. Are there students tell you are good at doing things?

25. Are there students explain the rules of a game if you didn't understand them?

26. Are there students choose you on their team at school?

\section{Factor 2: Adult support at school}

27. At school, there is an adult cares about me

28. At school, there is an adult listens to me when I have something to say

29. At school, there is an adult tells me when I do a good job

30. At school, there is an adult believes I will be a success

Factor 3: Adult support in community 
31. Away from school, there is an adult really cares about me

32. Away from school, there is an adult believes that I will be a success

33. Away from school, there is adult tells me when I do a good job

34. Away from school, there is adult I trust

Factor 4: Adult support at home

35. At home, there is adult wants me to do my best

36. At home, there is adult who is interested in my school work

37. At home, there is a adult believes that I will be a success

38. At home, there is adult listens to me

Factor 5: Autonomy experience

39. Home and school, I do things at home that make a difference

40. Home and school, I do things at my school that make a difference

41. Home and school, I help my family make decisions

42. Home and school, at school, I help decide thinks like class activities or rues

\section{Factor 6: Prosocial Peers}

43. My friends, try and do what is right

*44. My friends, get into a lot of trouble

45. My friends do well in school

Factor 7: Meaning participation in community life

46. Away from school, I am a member of a club, sports team, church, or other group

47. Away from school, I take lessons in music, art, sports, or have a hobby

*Item 44 has low response rate, is therefore deleted 


\section{References}

Ackerman, B. P., Brown, E. D., \& Izard, C. E. (2004). The relations between persistent poverty and contextual risk and children's behavior in elementary school. Developmental Psychology, 40(3), 367-377.

Beam, M. R., Gil-Rivas, V., Greenberger, E., \& Chen, C. (2002). Adolescent problem behaviour and depressed mood: Risk and protection within and across social contexts. Journal of Youth and Adolescence, 31(5), 343-357.

Belgrave, F. Z., Chase-Vaughn, G., Gray, F., Addison, J. D., \& Cherry, V. R. (2000). The effectiveness of a culture- and gender- specific intervention for increasing resiliency among African American preadolescent females. Journal of Black Psychology, 26(2), 133-147.

Benard, B. (1997). Turning It Around for All Youth: From Risk to Resilience (No. EDOUD-97-7). Washington, DC: Office of Educational Research and Improvement.

Benard, B. (2004). Resiliency: What we have learned. Retrieved 24 September 2007, from http://cye.colorado.edu/review.pl? $\mathrm{n}=206$

Bolognini, M., Plancherel, B., Bettwshart, W., \& Halfon, O. (1996). Self-esteem and mental health in early adolescence: Development and gender difference. Journal of Adolescence, 19, 233-245.

Broderick, P. C., \& Korteland, C. (2002). Coping style and depression in early adolescence: Relationships to gender, gender role, and implicit beliefs. Sex Roles, 46(7/8), 201-213.

California Department of Education. (2004). California Healthy Kids Survey: America: California Safe and Healthy Kids program office.

Doll, B., \& Lyon, M. (1998). Risk and resilience: Implications for the delivery of educational and mental health services in schools. School Psychology Review, 27(3), 348-363.

DuBois, D. L., Burk-Braxton, C., Swenson, L. P., Tevendale, H. D., Lockerd, E. M., \& Moran, B. L. (2002). Getting by with a little help from self and others: Selfesteem and social support as resources during early adolescence. Developmental Psychology, 38(5), 822-839.

Frost, J., \& McKelvie, S. (2004). Self-esteem and body satisfaction in male and female elementary school, high school, and university students. Sex Roles, 51(1/2), 45-54.

Frydenberg, E., \& Lewis, R. (1993). Boys play sport and girls turn to others: age, gender and ethnicity as determinants of coping Journal of Adolescence 16(3), 253-266.

Garmezy, N., Masten, A. S., \& Tellegen, A. (1984). The study of stress and competence in children: A building block for developmental psychopathology. Child Development, 55, 97-11.

Gilligan, C. (1982). In a different voice. Cambridge, UK: Cambridge University Press.

Hampel, P., \& Petermann, F. (2005). Age and Gender Effects on Coping in Children and Adolescents. Journal of Youth and Adolescence, 34(2), 73-83.

Hampel, P., \& Petermann, F. (2006). Perceived stress, coping, and adjustment in adolescents. Journal of Adolescent Health, 38, 409-415.

Heyman, G. D., \& Legare, C. H. (2004). Children's beliefs about gender differences in the academic and social domains. Sex Roles, 50(3/4), 227-239. 
Hill, J. P., \& Lynch, M. E. (1983). The intensification of gender-related role expectations during early adolescence. In J. Brooks-Gunn \& A. Petersen (Eds.), Girls at Puberty. New York: Plenum.

Jacobs, J. E., Lanza, S., Osgood, D. W., Eccles, J. S., \& Wigfield, A. (2002). Changes in children's self-competence and values: Gender and domain differences across grades one through twelve. Child Development, 73(2), 509-527.

Ladd, G. W. (1999). Peer relationships and social competence during early and middle childhood. Annual Review of Psychology, 50, 333-359.

Luthar, S. S. (Ed.). (2003). Resilience and vulnerability: Adaptation in the context of childhood adversities. New York: Cambridge University Press.

Luthar, S. S., \& Cicchetti, D. (2000). The construct of resilience: Implications for interventions and social policies. Development and Psychopathology, 12, 857885.

McBride, C. (1995). School-level application of a social bonding model to adolescent risk-taking behaviour. Journal of School Health(65), 2.

Miller, J. (1986). What do we mean by relationship? Wellesley, MA: Stone Center, Wellsley Colleage Press.

Plancherel, B., \& Bolognini, M. (1995). Coping and mental health in ealry adolescence. Journal of Adolescence, 18, 459-474.

Prelow, H. M., Weaver, S. R., \& Swenson, R. R. (2006). Competence, self-esteem, and coping efficacy as mediators of ecological risk and depressive symptoms in urban African American and European American youth. Journal of Youth and Adolescence, 35, 507-517.

Roeser, R. W., Eccles, J. S., \& Sameroff, A. J. (2000). School as a context of early adolescents' academic and social-emotional development: A summary of research findings. The Elementary School Journal, 100(5), 443-549.

Rutter, M. (1984). Resilient children. Why some disadvantaged children overcome their environments, and how we can help. Psychology Today, March, 57-65.

Rutter, M. (1987a). Psychosocial resilience and protective mechanisms. American Jouranl of Orthopsychiatry, 57, 316-331.

Rutter, M. (1987b). Psychosocial resilience and protective mechanisms. American Journal of Orthopsychiatry, 57, 316-331.

Smith, C., \& Carlson, B. E. (1997). Stress, coping, and resilience in children and youth. The Social Science Review, 71(2), 231-256.

Størksen, I., Røysamb, E., Møum, T., \& Tambs, K. (2005). Adolescents with a childhood experience of parental divorce: a longitudinal study of mental health and adjustment. Journal of Adolescence, 28, 725-739.

Torsheim, T., Aaroe, L. E., \& Wold, B. (2001). Sense of Coherence and schoolrelated stress as predictors of subjective health complaints in early adolescence: interactive, indirect or direct relationships. Social Science \& Medicine, 53, 603-614.

Tusaie, K., Puskar, K., \& Sereika, S. M. (2007). A predictive and moderating model of psychosocial resilience in adolescents. Journal of Nursing Scholarship, 39(1), 54-60.

Watkins, D., Dong, Q., \& Xia, Y. (1997). Age and gender differences in self-esteem of Chinese children. Journal of Social Psychology, 137, 374-379.

Werner, E. E. (1990). Protective factors and individual resilience. In S. J. Meisels. \& J. P. Shonkoff. (Eds.), Handbook of early childhood intervention (pp. 97-116). New York: Cambridge University Press. 
Werner, E. E. (1992). The children of Kauai: Resiliency and recovery in adolescence and adulthood. Journal of Adolescent Health, 13, 262-268.

Wild, L. G., Flisher, A. J., Bhana, A., \& Lombard, C. (2004). Associations among adolescent risk behaviours and self-esteem in six domains. Journal of Child Psychology and Psychiatry, in press. 